\title{
LASER-SCANNER SURVEY OF STRUCTURAL DISORDERS: AN INSTRUMENT TO INSPECT THE HISTORY OF PARMA CATHEDRAL'S CENTRAL NAVE
}

\author{
N. Bruno ${ }^{a}$, E. Coïsson ${ }^{a^{*}}$, M. Cotti ${ }^{\text {a }}$ \\ ${ }^{a}$ University of Parma, Department of Engineering and Architecture, Parco Area delle Scienze 181A, 43124, Parma, Italy - \\ (nazarena.bruno, massimo.cotti)@studenti.unipr.it, (eva.coisson)@unipr.it
}

Commission VI, WG VI/4

KEY WORDS: Parma Cathedral, Laser Scanner, Structural Disorders, Historical Monitoring, Structural Analysis

\begin{abstract}
:
This paper presents the use of laser scanner derived data for the study of the structural disorders in the central nave of the Parma Cathedral. An accurate three-dimensional model of the entire nave was realized to investigate deformations, in order to reconstruct the original conformation and the subsequent evolutions, also in comparison with previous surveys. Specifically, for the analysis presented in the paper, seven scans were performed, one for each bay: the results allowed to compare the deformations on the seven vaults, on the transverse and diagonal arches, giving first hints on the possible differences in the behaviour between the different elements. The measures on the levels of floor and pillars bases were analysed in a historical monitoring approach, in order to retrace the evolution of the differential settlements in time, since the construction of the building. Moreover, a structural analysis has been carried out on one transverse arch with distinct element analysis, with two different approaches. In one case, the structure was inserted exactly as surveyed, and then subjected to the actions. In the second case, the original geometry, before the deformation, was retraced through a parametric approach and the structural analysis basically started at the beginning of the building's life, thus trying to model not only the present structural situation, but also the path which led to the current deformation. The results were particularly meaningful as they showed that in the first case, disregarding the footsteps of history, the stress pattern inside the masonry was very different from the one obtained in the second case, which is more likely to represent the present conditions.
\end{abstract}

\section{INTRODUCTION}

The more buildings are old, the more it is difficult to find complete archival documentation about their construction process, the damages and modifications they suffered in time, and the evolution of their different parts. In these cases, most meaningful information can be found directly on the building itself, which can be seen as a document of its own history. The problem stands in how to read and interpret these pieces of information: here comes the important role of geomatics and survey, as an instrument not only to inspect the present geometry and conditions, but that - through it and with the joint effort of architecture historians, restorers and structural experts - can also supply new elements to compose a more complete picture of the possible historical process which brought the building to be what we see now.

The principal purpose of the survey presented in this paper was the analysis of the general structure and deformation of the central nave of the cathedral of Parma at the current state and the integration of existing documentation. The church dates back to the end of the $11^{\text {th }}$ century but, as most historical buildings, has been subjected to changes, additions, damages and repair works throughout its life. At present, the church has a Latin cross with three naves covered by cross vaults on a rectangular basis. The original conformation is still uncertain, but, after decades of debate, it is considered most likely that the original vaults were on a square base and then collapsed in occasion of the strong 1117 earthquake (Blasi and Coisson, 2006). Lateral chapels and vaults over the matroneums were added in the following centuries, together with higher buttresses and tie rods for the stability of the already deformed nave.

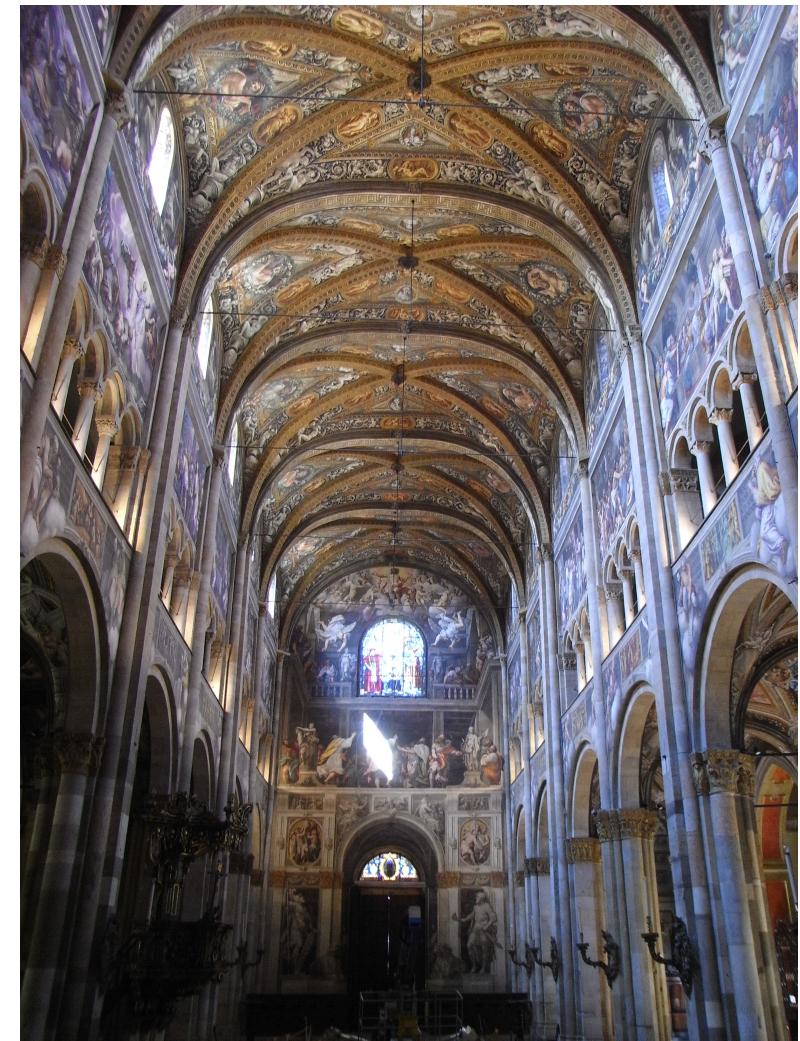

Figure 1: A view of the central nave of the Parma Cathedral.

\section{LASER-SCANNER SURVEY AND MONITORING} ISSUES 
Due to the complexity of this type of architectures, instrumental surveys, such as laser scanning and photogrammetry, are usually implemented to obtain exhaustive $3 \mathrm{D}$ reconstruction of architectural details, parts or of the whole building. Such techniques allows remote measurements: thus direct accessibility of all the parts of the building is not requested. In particular, terrestrial laser scanner (TLS) allows, in a relatively short time, acquiring millions of points, from which derive complete, accurate and high detailed 3D models. In addition, TLS offers advantages such as unnecessity of targets, acquisition of high resolution/high quality images of the object thanks to sophisticated integrated cameras, permanent visual records and high spatial data density (Mukupa et al., 2017).

Thanks to these capabilities, TLS is largely used in architectural survey finalized to documentation and knowledge. Conversely, as far as structural monitoring is concerned, despite the increasing interest gained in the recent years (Camarda et al., 2010; Marani et al., 2016; Fantoni et al., 2017; Mukupa et al., 2017), TLS application is more limited.

Up to now, deformation analysis are performed with high precision instruments, such as total stations and levels, that acquire data characterized by millimetre precision but with limited spatial density, since they make discrete and sample measures.

Conversely, TLS allows extending the spatial coverage by detecting the entire visible surface: it is so possible to gather a large amount of data nearly continuously in space, being able to compare point clouds referred to different epochs. Despite of these clear pros, many cons have to be taken into consideration (Holst \& Kuhlmann, 2016; Acikgoz et al., 2017):

- Internal systematic errors of the laser scanner that lead to systematic effect in the point cloud and noise in the detected points. It is difficult to separate actual deformations from measurements errors (Holst \& Kuhlmann, 2016). These effects depends on the accuracy of the instrument therefore, for high precision deformation analysis, a pre-calibration of laser scanner is recommended.

- Noise of the raw point cloud data that makes the single point precision much less accurate compared with conventional survey techniques (Mukupa et al., 2017). However, although the individual measure is low in precision, the model of the entire point cloud, thanks to its high data redundancy, can achieve a much higher precision and represent an effective way for describing the change of shape of a structure. (Gordon \& Lichti, 2007).

- Comparing different point clouds, acquired at different times, requires to register the data in the same reference system, with an accurate and stable datum, in order to avoid displacement errors that can invalidate the comparison.

- Choosing the best method, depending on each case, for computing displacement within the many methods and implemented algorithms (e.g. compare point-topoint, point-to-surface or surface-to-surface). (Mukupa et al., 2017).

It is so clear that it is not sufficient to analyse the raw point clouds, but a complex post-processing is necessary to make data comparable.

The average range of accuracy achieved in several case studies, as reported in (Mukupa et al., 2017), varies from centimetre to millimetre, depending on the scanner used and on the calibration, the measurements conditions, the correctness of georeferencing and the method of point cloud data processing employed for deformation analysis.
As demonstrated in some case studies (Fregonese et al., 2013; Lindenbergh, 2013) scan registration is a key point of the whole monitoring process. Registration influences the accuracy of the point clouds and so the values of deformation detected. Therefore, it is important to have good starting datasets, referring to the same stable reference system, in order to compare easily the scans.

\subsection{The previous surveys of the Parma Cathedral}

The history of Parma Cathedral has been long inspected, but still sees some crucial aspects debated and unclear. One aspect that has been only partially analysed, in order to reconstruct the original conformation, is the present, deformed, geometry.

Since the eighties of the twentieth century, some surveys have been performed using modern techniques. In particular a photogrammetric survey of the entire cathedral was performed between 1989 and 2004 (Giandebiaggi et al., 2006). It is the only complete survey of the building existing today.

Further investigations on the structure were performed in occasion of the 2006 restoration and concerned:

- high precision levelling of the crypt and the nave (Coisson et al., 2006),

- coring of some areas in order to obtain the composition of the foundation subsoil (Coisson et al., 2006),

- total station survey of the out of plumb of the pillars in the central nave (Giandebiaggi et al., 2006),

- structural monitoring with inclinometer and crack gauges installed on the main cracks (Coisson et al., 2006),

- TLS survey of the third and fourth bay (starting from the façade) in order to verify the serious deformation of the vaults shown by the previous photogrammetric survey (Giandebiaggi et al., 2006).

In order to analyse the general structure and deformation of the central nave, a new accurate three-dimensional model of the entire nave, as integration and update of the previous surveys, was necessary.

For this reason, a 3D laser scanner survey has been carried out and TLS data were used to reconstruct the actual shape of the central nave, paying particular attention to the deformed profiles of vaults and arches and to their interactions with the supporting pillars and the whole structure.

In addition, the outcomes of the survey were used to make a qualitative comparison with deformation data gained from the 2006 survey campaign. The evaluation has been only qualitative, since previous surveys had been made with traditional techniques without referring to a stable and recognisable reference system. In this way, it was impossible to recognise on the actual point cloud the exact points measured in the previous surveys.

\subsection{The new survey campaign of Parma Cathedral}

The survey started from the execution of a topographical network all around and inside the cathedral. Each station point has been signalized with steel nails sealed on the paving, in order to make the reference system stable and recognisable in time. This was mandatory in order to implement the survey in time: although in this phase the object of the survey was only the nave, the whole cathedral is interested by damage processes, so the survey campaign will be extended in the future to the entire building.

Moreover, starting from this survey campaign, the aim is to begin a periodic monitoring of the structure, either by laser scanner or other instruments. In this way, all future measures may be referred to the same topographical network: it will be 
possible to co-register data gained from different surveys epochs and with different techniques (such as total station, levels, laser scanner, close-range photogrammetry, UAV photogrammetry, etc.) and easily compare them together.

The survey of the topographical network has been carried out twice: both with Topcon Image Station IS2 total station and Leica C10 laser scanner, in order to achieve greater accuracy on the final compensation, thanks to the redundancy of observations. Twenty-two stations were materialized, as shown in figure 2. The least squares compensation of the network was made with the software Calge (Forlani \& Mussio, 1986), considering both total station and laser scanner observations. The final value obtained for sigma naught was $\sigma_{0}=1.8$, with mean accuracy of local coordinates of station points of ca. 2.13 $\mathrm{mm}$, which can be considered acceptable for most monitoring activities if very high precisions are not required.

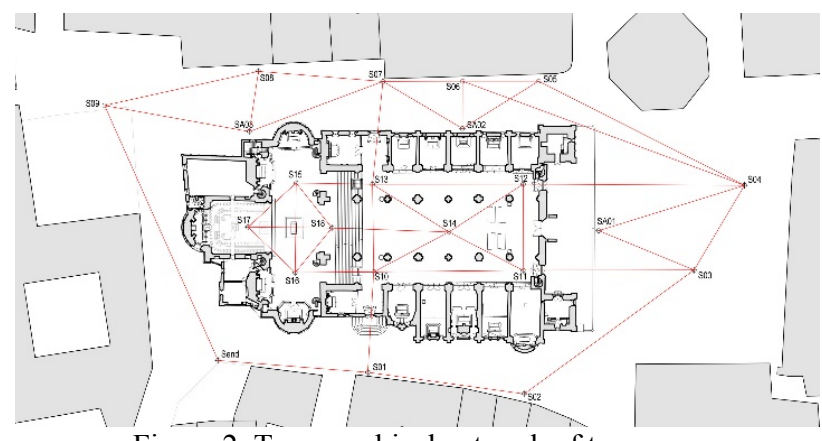

Figure 2. Topographical network of traverses.

The topographical network was then georeferenced on the basis of GPS survey of three vertices, placed in the two squares at the opposite corners of the building. The compensated and georeferenced vertices coordinates were used to co-register the eighteen scan stations, obtaining a general point cloud of the cathedral. Further seven high resolution scans (one for each bay in order to minimize occlusions and gain the highest possible resolution) were performed in the central nave, referring them to the general topographical network described before.

\subsection{Data processing}

Point clouds registration and georeferencing were made with Leica Cyclone software. Then, data were exported in Autodesk ReCap 360 PRO and here filtered, in order to eliminate noise and outliers, and segmented. For data analysis the Autodesk AutoCAD software has been used, since it was necessary to examine sections of the point cloud. In particular a false-colours plan of the vault was produced in order to evidence differences in height and global deformations of the vaults (Fig. 3).

For instance, it is interesting to notice the clear difference between the north and south transept vaults, the north one being substantially more deformed than the south one: indeed, the historical archives report of a reconstruction of the south transept vault, carried out at the end of the $18^{\text {th }}$ century due to severe seismic damages suffered in the previous decades. More detailed analysis were performed by the extraction of the longitudinal section of the nave and the cross sections of all the arches in order to assess the structural problems (Figure 4).

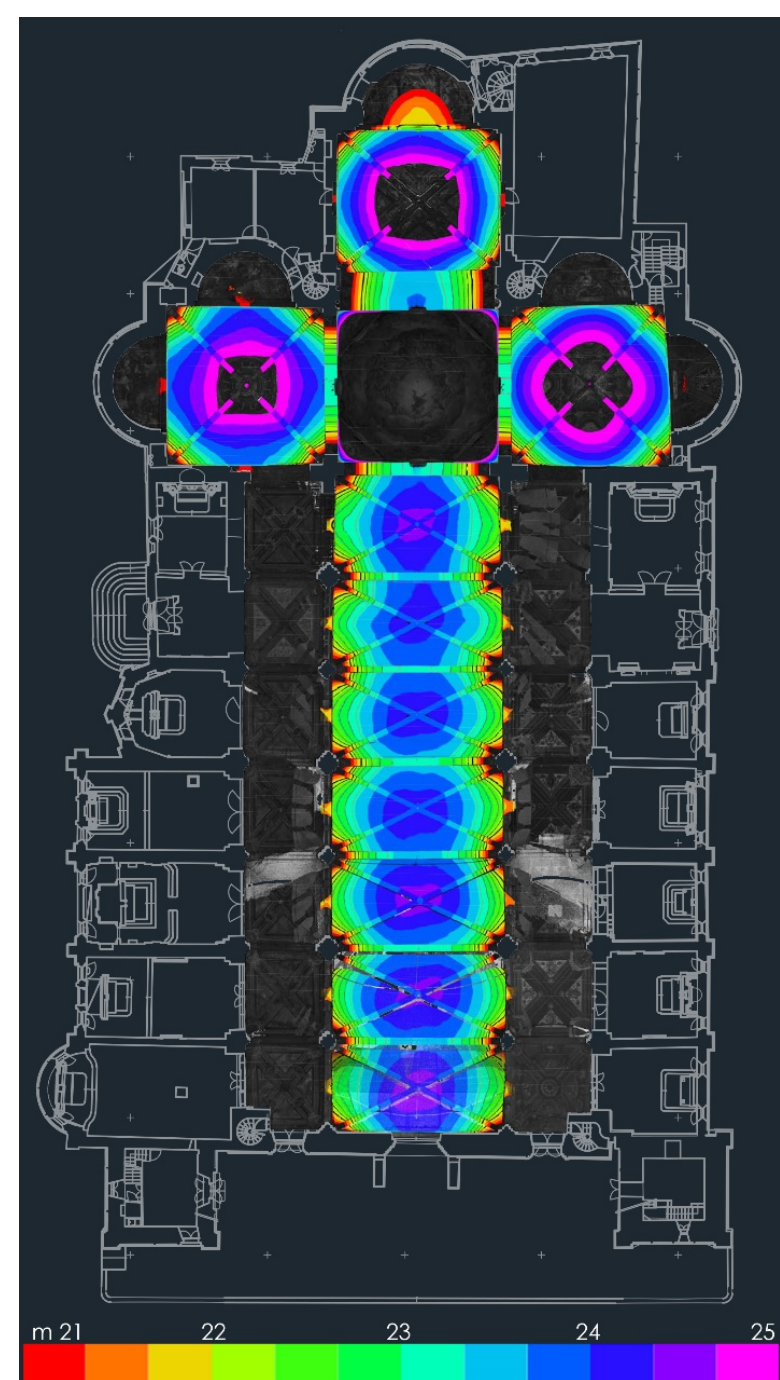

Figure 3. False-colours plan of the vault, evidencing the differences in height and the global deformations.

Particular attention was paid to the deformed profiles of the arches and to differential subsidence of pillars. Points of detail were measured on the floor, at the bases of the pillars and in correspondence of intermediate and upper capitals.

From these measurements, the lasting deformation state of the central nave clearly appears. In particular the outcomes show:

- Progressive structural settlement of the floor towards the dome, due to the weight of the dome itself, with a maximum of 9 centimeters. Globally, the settlement is higher in the South side, as already highlighted in 2006 survey, probably because of the presence of an ancient canal on this side.

- Lowering of the level of the upper capitals in the central part of the nave (fifth bay) and not progressive decrease towards the dome, as observed for the floor.

- Decrease of pillars out of plumbs towards the dome, probably due to the stabilizing function of the wright of the dome, with exception of the fifth pillars, which have the higher value of out of plumb (north $=223$ $\mathrm{mm}$ and south $=331 \mathrm{~mm}$ ).

While the results of the lowering of the floor are comparable with the ones of 2006 survey, having similar trends and values, the measurements of the capital quotes and, above all, of the out of plumbs, are very different and incongruous. 


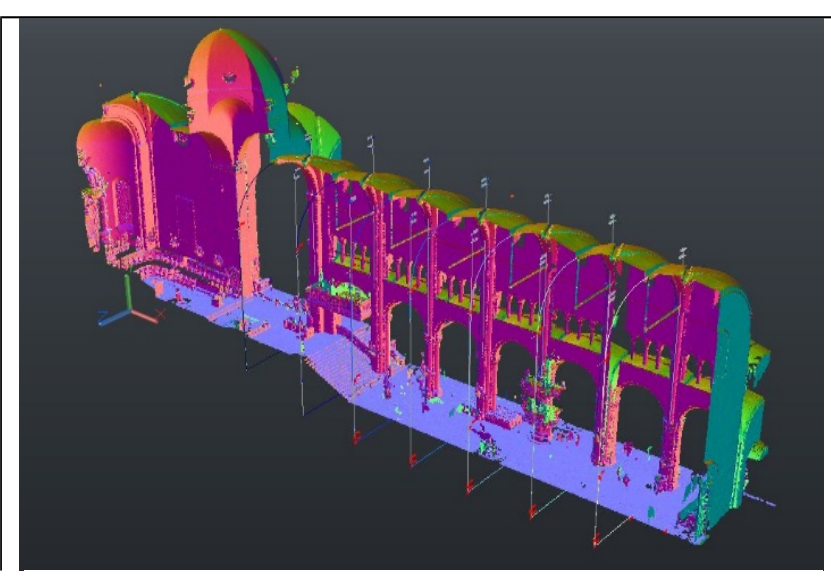

25
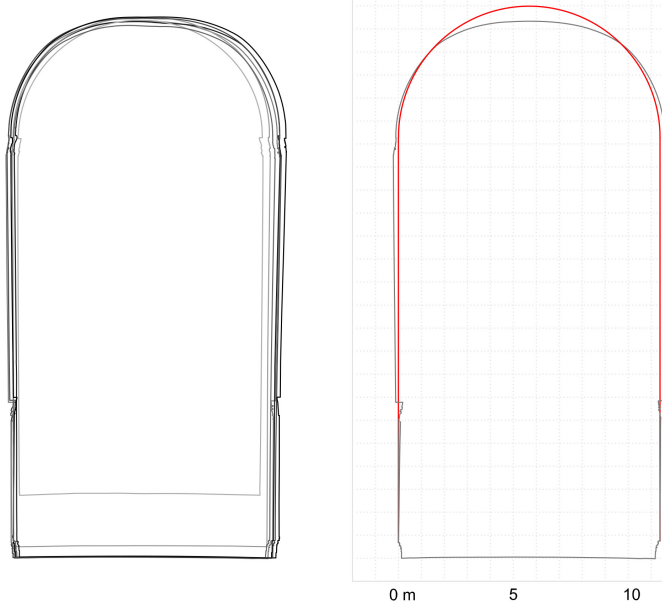

Figure 4. Longitudinal section of the point cloud which shows the south side of the nave and the arches profiles. Below: the arches profile and (in red) the reconstruction of the undeformed shape.

It is so reliable to suppose that the principal cause of these incongruences is not the accuracy and the precision of laser scanner data, but the difficult to precisely sample the discrete points measured in the survey of 2006. For the reconstruction of the floor trend, indeed, more complete information were available about the detected points. In addition, the variability of the values referred to floor height is less, so the precise identification of the sample point on the cloud is less crucial. On the contrary, as regards the out of plumb, the lack of knowledge of the calculation method and the specific point measured, lead to non-negligible inconsistencies.

In this case, having too little information about the previous surveys and being impossible to register all the data in a same reference system, it seems risky to compare and make monitoring observations on the basis of such different data.

\section{LASER SCANNER DERIVED DATA AND HISTORICAL MONITORING}

\subsection{The historical monitoring approach}

The laser scanner survey, as previously shown, is particularly suitable to analyse the deformation state of a structure, but as these evolve very slowly in time, it is difficult to catch differences in deformations between two succeeding surveys, thus using laser scanning as an instrument for static structural survey. Even when some data can be obtained, in case of fast evolving damage or when the time span between the measurements is particularly long, the results only allow to take a glimpse of the present speed of evolution of the ongoing damage mechanisms (Roca, 2004). This is of course important but not conclusive to assess an overall trend and to understand if the damage is increasing or settling, which is the first piece of information needed for the definition of the urgency of an intervention (Coisson and Ottoni, 2015, ICOMOS, 2005).

Despite this, the same data obtained from a single laser scanner survey can give useful information not only to analyse the present conditions but also to inspect the evolution of the damage in time, applying the so-called historical monitoring (Coisson and Ottoni, 2013).

In order to reach this aim, though, an interdisciplinary approach needs to be applied and, in particular, a thorough historical analysis must be carried out specifically on the elements which show the most significant deformations. Indeed, in an ancient building, the "footsteps of history" (Roca, 2004) can be found and read not only in the structural elements, but also in decorative or finishing elements: pillars and floors, frescoes and walls, corniches and arches, they all can suffer specific deformations which can be compared among them taking into consideration the period in which they were first realized. This allows comparing the different deformations surveyed on the elements built in different periods and thus retracing the evolution of damage in time.

\subsection{The settlements of the central nave in time}

Typically the damage mechanisms related to the soil-structure interaction have a slow evolution in time and are particularly suitable for the application of a historical monitoring approach. In the Parma Cathedral, the main soil settlements problems are connected to the weight of the dome and supporting structures, which causes on the soil underlying the four main pillars a significantly larger compression state than in the other parts of the building. Therefore, the differential settlements between this area are the surrounding ones caused deformations which have evolved in time.

In order to apply the historical monitoring, elements built in different periods and which were characterized by an original horizontality must be found. In this case, the main elements considered were the pillars with their bases and capitals, dating back to the first period of construction at the end of the $11^{\text {th }}$ century, and the stone flooring, inserted in the $16^{\text {th }}$ century. Both elements now show an inclination towards the central dome area, but the precise data obtained from the laser scanner survey allow to inspect the differences and deduce some quantitative information on the evolution of the settlement in time.

The data are relative to a reference point placed in the centre of the façade and of course all the calculated settlements are differential and not absolute, but these are the data that most affect the structures. As shown in figure 5, despite the overall settlements are higher in the south side, as previously highlighted, the differential settlements are larger on the north side. Moreover, the evolution on the north side seems for most pillars getting to a stable condition. On the contrary, on the South side the trend appears to be increasing. The changes in the use of the aforementioned canal on this side might have influenced also the behaviour in time. 


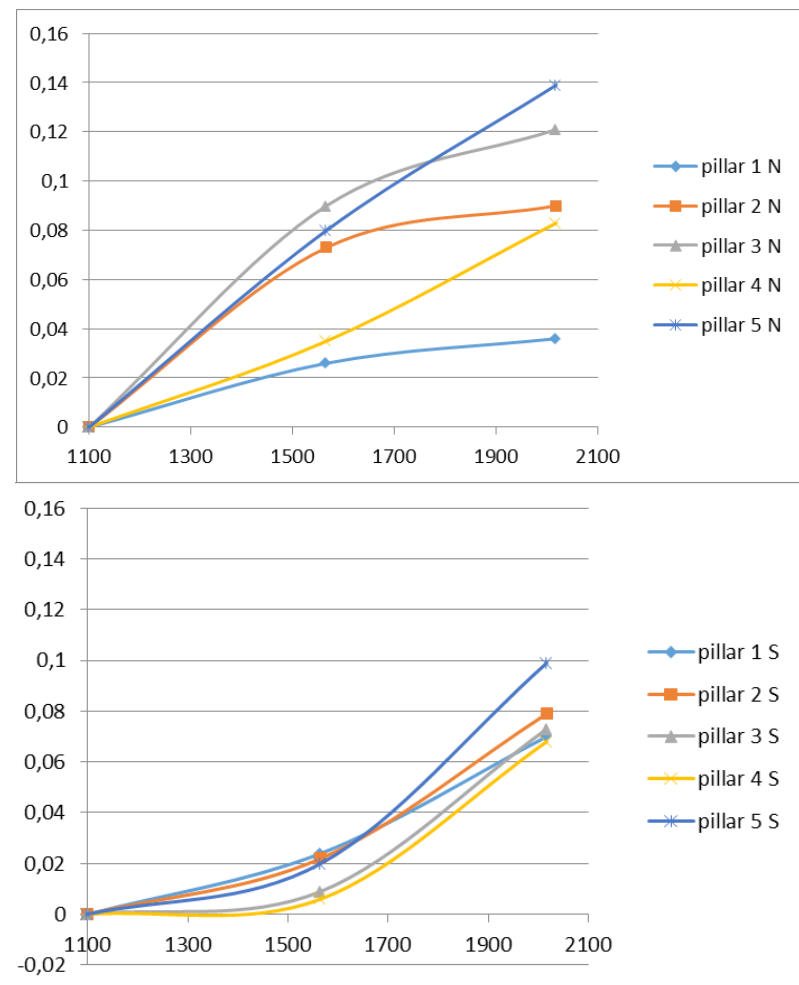

Figure 5. The differential settlements of the North and South colonnade pillars show very different behaviours

\section{FROM LASER SCANNER POINT CLOUD TO STRUCTURAL MODELS}

\subsection{The risks of an automated approach}

The deformation state of the central nave obtained through the laser scanner survey was also used in order to carry out numerical models for the assessment of the stability conditions. In this type of operation, though, some caution has to be taken in order to avoid some risks which an automated approach can induce. Indeed, the always greater space that the electronic instruments for architectural survey on one side and for structural elaboration on the other are gaining in the scientific and professional world, is leading towards procedural practices that directly use the geometric survey, possibly in the form of the Building Information Modeling, as a basis for the structural modeling (Castellazzi et al., 2015). But an existing building and therefore also the individual components that constitute it has already undergone, in time, numerous modifications: earthquakes, settlements, material deformation, are in fact among the factors that most commonly modify the original shape and transform the building into what the eye (and tools) see today, modifying at the same time what is not seen, i.e. the state of internal stress of the material (Roca, 2005; Pelà et al., 2006; Coisson et al., 2013).

The reduction of processing times that ensues from an automated approach makes it very attractive, but in the context of structures that have considerable structural deformations, a non-critical analysis of the data of the survey may however be a source of a wrong interpretation of the shapes that are currently visible and of the real structural conditions.

The laser scanner, and geometric models generated with it, must instead be integrated with critical-historical information in order to avoid the generation of structural models that appear only formally correct but are in danger of losing sight of the historicity that makes these buildings special. Firstly, the study cannot avoid the understanding of structural typologies, proportions and constructive shapes, not only to rediscover the project originally conceived, but also to correctly identify the successive deformations and kinematics occurred in time on the structures.

Etymologically, the monument becomes a document of itself, representing a full-scale model, in time subjected to actions that must be first of all identified and then inserted into the virtual model, so that the model can correctly retrace the path of the building through history, getting, hopefully, to similar results. It is therefore necessary to avoid that too many automation and computer facilities lead to consider a model defined by survey as ready to use as a basis for subsequent models intended for the structural calculation, loosing this important piece of information.

The critical comparison between the results obtained following the two paths in the present case study thus appears as a cue of reflection aimed at highlighting the possible problems that certain technological facilities, if not properly controlled and critically managed, can induce in the study of existing masonry buildings.

\subsection{The model of the central nave of the Parma cathedral}

The structure of the arches, to date, has a shape not consistent with the one thought by the ancient architects; the survey data analysis has highlighted a rotation of the longitudinal walls outwards, the cause of which is to be found in a variety of factors that have taken place in the course of time (Blasi and Coisson, 2006):

- the transverse thrusts of the vaults of the central nave (emphasized in some cases by earthquakes)

- the original lack of upper buttresses (built after the first large earthquake in 1117)

- the presence of differential vertical settlements between the north and south sides.

The overall result is the occurrence of a loss of verticality of the main pillars of the arches that reaches values of about $20 \mathrm{~cm}$. This has produced, in the arched structures, a loss of shape with a large lowering in the crown of the arches, which also affected the overlying cross vaults.

Considering these large deformations, for the present study, an approach based on rigid block analysis and discontinuous deformation analysis on two-dimensional plane-type elements was applied (Thavalingam et al, 2001, Giordano et al., 2002), in the UDEC environment. In general, the approach is applicable to all those systems that can be considered as an assemblage of elements (or blocks), generally rigid, which interact with each other (Lourenço, 2008, van Noort, 2012, Lourenço et al., 2007). The contiguous blocks interact with constraints of no-tension, unilateral type contact, elastic in compression; the sliding between the blocks considers the effect of friction.

In keeping with the classic approach to this method, the real masonry texture of the arches was faithfully reproduced in the model (Casolo, 2009). The main issue, as previously exposed, was whether to adopt, as a base for the structural model, the present, deformed configuration or the original, undeformed one (Shi and Goodman, 1998). Both options were followed, in order to demonstrate the role of the deformation in the understanding of the static condition of a historic building.

A preliminary phase was then needed for the definition of the original undeformed geometry, starting from the present laser scanning survey. A detailed curve was extrapolated (Zerlenga, 2008), representing the current deformations in the arches and in the pillars on which they rest. 
The processing of survey data in computer graphics (Software Rhinoceros and Plug-in Grasshopper/GH, Caraccia 2006, Coak, 2008) has allowed the extrapolation of the geometric data of the individual blocks that compose the investigated structure and the generation, in the environment of UDEC two-dimensional calculation, of the corresponding model, purged of detail elements that are not structurally relevant.

For the reconstruction of the undeformed geometric state, presumably designed and built by the ancient builders (apart from normal uncertainties related to the manual construction), an integration was carried out between the geometrical information, investigated by the laser scanner survey, with historical information from archival researches and studies on the constructive practices (Becci and Foce, 2002), materials and to the successive stages of construction and modification.

At the base of this process, the following assumptions have been made:

- native verticality of the pillars, reconstructed starting from the position on the ground (assuming that there were no horizontal movements of the base);

- rigid rotation of the pillars, which allows to geometrically reconstruct the height of the springer of the undeformed arch;

- compensation of differential settlements between the two sides;

- undeformed structure considered as a round arc (typically Romanesque).

The two models, one relating to the original conformation, the second relative to the current conformation, were then adopted (Figure 6). For both of them, the following mechanical characteristics of the materials and boundary conditions have been considered:

- Materials:

- $\quad$ Stone: Density $27 \mathrm{kN} / \mathrm{m}^{3}$, friction angle $35^{\circ}$

- $\quad$ Brick: Density $18 \mathrm{kN} / \mathrm{m}^{3}$, friction angle $30^{\circ}$

- round arch discretized, in both configurations of analysis, in 50 voussoirs;

- extrados loads for the presence of the cross vaults (descending values from the crown to the impost)

- modeling of the upper outer walls in order to follow the effect of vertical compression (action of the loads from the roof structure).
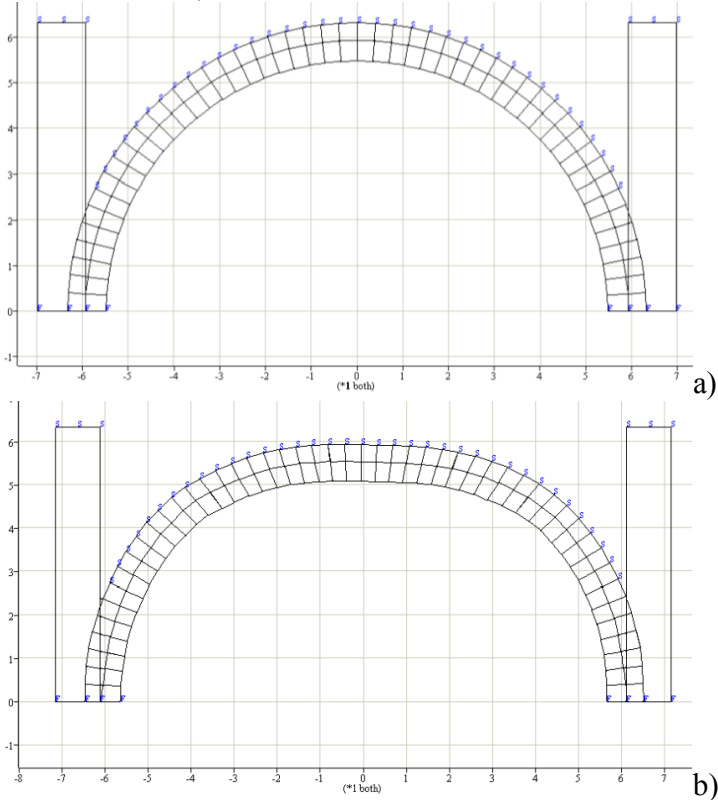

a)

Figure 6: The undeformed (a) and deformed (b) conformations adopted as starting points for the numerical analyses.

\subsection{The results of the numerical structural models}

For the analysis of the undeformed model the horizontal displacements of the imposts of the arch have been imposed in accordance with the results of the geometric survey: the north springer was moved $12 \mathrm{~cm}$ to the left and the south one $23 \mathrm{~cm}$ to the right.

The study on the undeformed configuration has followed two distinct phases: the first one, with the application of gravitational loads, in order to simulate the behavior of the structure and the initial application of the self-weight; the second one, with the application, through incremental steps, of the movements of the arch springers, as previously identified, to reconstruct the path of the structure through the centuries.

The results (Figure 7) show that the arch geometrical configuration reproduced is in good accordance with the present overall deformative status; moreover, some openings in the contacts between the blocks were evidenced, which find correspondence in the state of the places. This approach has thus allowed to take globally into consideration the effects of settlements, earthquakes, creep of the masonry, constructional modifications, which otherwise could not be individually identified.

The modeling of the deformed configuration, instead, consists of a single step procedure: the application of gravitational actions on already deformed structures. The results (Figure 8) show, as easily predictable, a final deformation slightly higher than the one obtained from the survey, as the latter was used as a starting point to which all the loads were added.

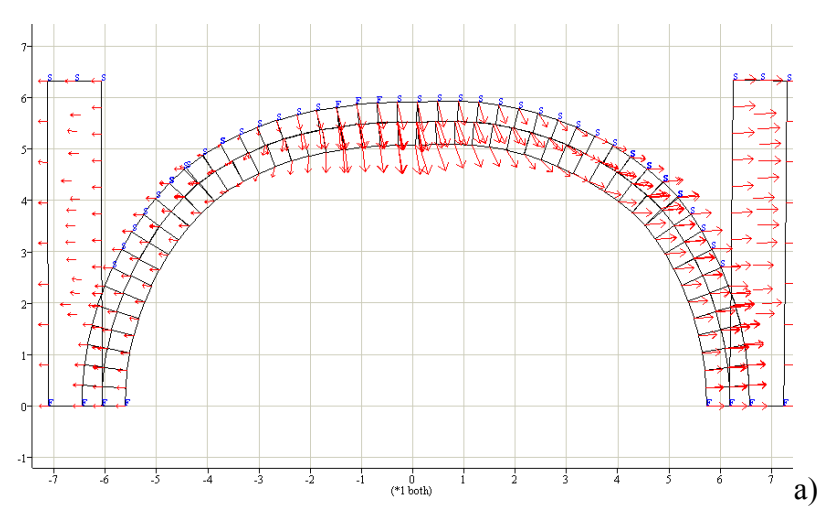

a)

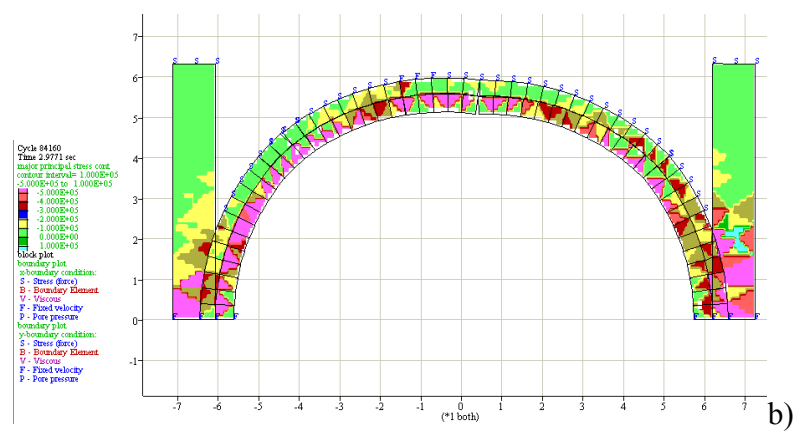

Figure 7: Model, in UDEC environment, starting from the original geometry with (a) an indication of the displacements (red) of the individual blocks due to the application of the loads history and (b) the principal stresses developed within the individual blocks. 

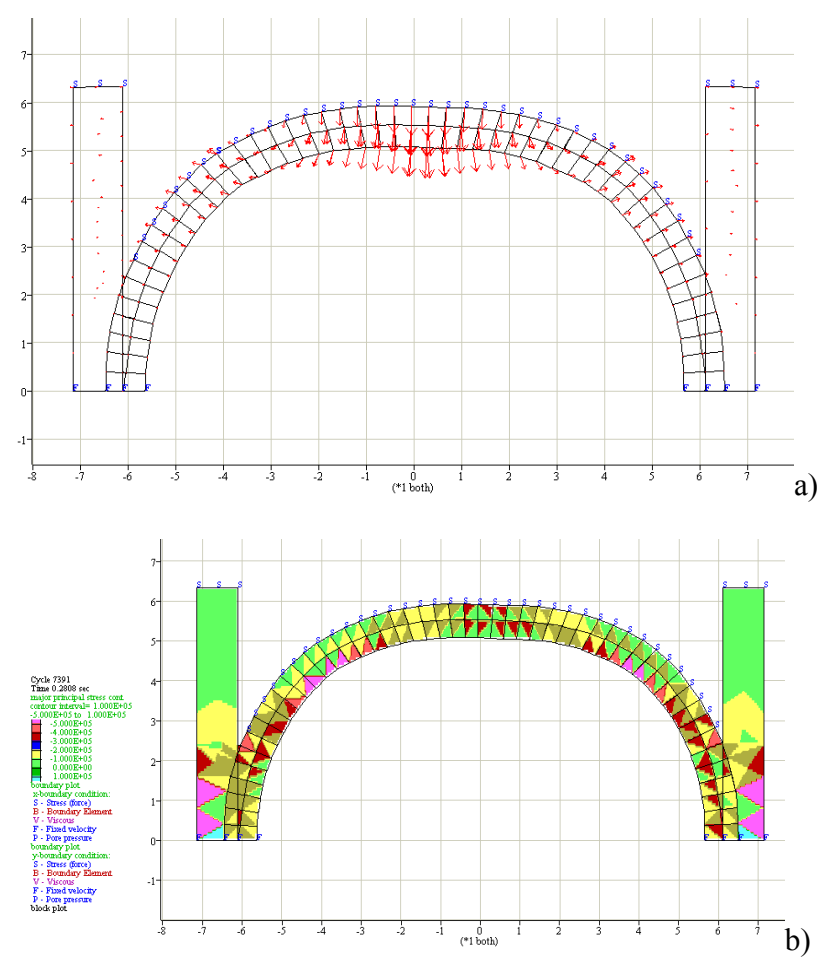

Figure 8: Model, in UDEC environment, starting from the present deformed geometry with (a) an indication of the displacements (red) of the individual blocks due to the application of the loads history and (b) the principal stresses developed within the individual blocks.

But the largest differences could be seen in the structural behaviour. In the first analyzed case, the imposition of changing boundary conditions allowed to follow the variations occurred in the interfaces and in the contact points, with the onset of fractures and reduction of the contact areas between the blocks. In the second case, this did not happen because, starting from a deformed geometrical configuration a priori, the interfaces of the blocks were continuous and the analysis has seen the appearance of only minor openings.

Even more meaningful is the comparison in terms of stresses: in the specific case of this study the peak compressive stresses obtained are approximately 6 times higher in the first modeling (starting from the undeformed configuration) than in the second one (starting from the deformed configuration).

This confirms the significant risks previously put forward: the procedures that see a direct and automatic relationship between the surveyed geometrical model and the virtual model for the numerical structural analysis run the risk of a substantial overestimation of the safety level, as well as of a limited effectiveness in representing and understanding the present situation and the path that lead to it (Pelà et al. 2006).

\section{CONCLUSIONS}

The study dealt with the possible uses of the data obtained from several survey campaigns on the Parma cathedral, the last of which was specifically carried out with laser scanning techniques for the present work. In particular, the application of this technique to structural static monitoring, to historical monitoring and to structural analysis were discussed.

The main outcomes reached can be summarized as follows: the geometrical survey highlighted the lasting deformation state of the central nave and gave first hints on the possible differences in the behaviour between the different elements;

- the measures taken at 11 years of distance were not completely consistent, also due to a lack of precise reference points, therefore their comparison could not be used to monitor the slow increase in deformation which most probably have occurred (also considering that some earthquakes happened in this period)

- the integration between the new precise survey and the historical information on the dating of the different parts of the building allowed to apply the socalled historical monitoring to the soil differential settlements, pointing out the different historical evolution of the North and South colonnade settlements;

- the comparison between structural distinct element analyses carried out on both deformed and undeformed structures evidenced that the increasing habit of transferring directly the 3D model from survey to numerical analyses can lead to worrying results which underestimate the risk level.

At the base of all the analyses illustrated there is the recognition of the fundamental role of the deformation in the understanding of the static condition of a historic building and thus the important role of the survey of these deformations.

The monument was used as a document of itself, as an experiment in full scale: knowing the results (only in terms of displacement) the tensional aspects were derived in order to define the current security level and the historical evolution was retraced in order to get a more meaningful idea of the overall trend of the structural disorders.

The hope is that the information provided in this period of rapidly changing technology, can prevent the spread of automated practices that dangerously oust the role of critical interpretation (inevitably human) of the data provided by machines.

Even if the deductions are not conclusive, the picture obtained through the combined application of a precision geometrical survey, archaeological stratigraphy of the built elements, structural considerations and analyses, allowed to reach a more comprehensive understanding of the evolution of the structures of the central nave, their behaviour in time and their present conditions. One more demonstration, if still needed, that dealing with these wonderful and composite buildings, an integrated approach is mandatory as, taken singularly, stylistic considerations, geometrical survey or structural analyses alone cannot explain the complexity instilled by history.

\section{REFERENCES}

Blasi, C., Coïsson, E., 2006. Il terremoto del 1117 e le conseguenze dell'architettura del XII secolo. La Fabbrica del Duomo di Parma, grafiche STEP editore, Parma, 2006.

Acikgoz, S., Pelecanos, L., Giardina, G., Aitken, J. \& Soga, K., 2017. Distributed sensing of a masonry vault during nearby piling. Structural Control and Health Monitoring, 24(3).

Camarda, M., Guarnieri, A., Milan, N. \& Vettore, A., 2010. Health monitoring of complex structure using TLS and photogrammetry. International Archives of Photogrammetry, 
Remote Sensing and Spatial Information Sciences, 38(5), pp. 125-130.

Coisson, E., Forlani, G., Montrasio, L. \& Roncella, R., 2006. I dissesti e la stabilità della fabbrica: analisi e controlli. In Blasi, C. \& Coisson, E., (editors). La fabbrica del Duomo di Parma. Stabilità, rilievi e modifiche nel tempo. Grafiche Step, Parma, pp. 259-285.

Fantoni, R., Almaviva, S., Caneve, L., Caponero, M., Colao, F., Ferri De Collibus, M., Fiorani, L., Fornetti, G., Francucci, M., Guarneri, M., Lazic, V., Palucci, A. \& Spizzichino, V., 2017. Laser scanners for remote diagnostic and virtual fruition of cultural heritage. Optical and Quantum Electronics, 49(120).

Forlani G. \& Mussio L., 1986. Test on Joint adjustment of geodetic and photogrammetric data. International Archives of Photogrammetry and Remote Sensing, vol. XXVI, part 3.1, Rovaniemi, 1986, 237-251. issn 0256-1840.

Fregonese, L., Barbieri, G., Biolzi, L., Bocciarelli, M., Frigeri, A. \& Taffurelli, A., 2013. Surveying and Monitoring for Vulnerability Assessment of an Ancient Building. Seonsors, 13(8), pp. 9747-9773.

Giandebiaggi, P., Belli, A., Vernizzi, C. \& Ghiretti, A., 2006. Rilievi della Cattedrale di Parma. In Blasi, C. \& Coisson, E., (editors). La fabbrica del Duomo di Parma. Stabilità, rilievi e modifiche nel tempo. Grafiche Step, Parma, pp. 209-257.

Gordon, S. \& Lichti, D., 2007. Modelling terrestrial laser scanner data for precise structural deformation measurement. Journal of Surveying Engineering, 133, pp. 72-80.

Holst, C. \& Kuhlmann, H., 2016. Challenges and present fields of action at laser scanner based deformation analyses. Journal of Applied Geodesy, 10(1), pp. 17-25.

Lindenbergh, R., 2013. Trends in detecting changes from repeated laser scanning data. Proceedings of the joint international symposia on deformation monitoring, Nottingham, United Kingdom, 9-10 September.

Marani, R., Nitti, M., Stella, E. \& D’Orazio, T., 2016. Monitoring of indoor environments by change detection in point clouds. Environmental, Energy, and Structural Monitoring Systems (EESMS), IEEE Workshop on.

Mukupa, W., Roberts, G.W., Hancock, C.M. \& Al-Manasir, K, 2017. A review of the use of terrestrial laser scanning application for change detection and deformation monitoring of structures. Survey Review, 49(353), pp.99-116.

Roca, P., 2004. Considerations on the significance of history for the structural analysis of ancient constructions. In Proceedings of IV Structural analysis of historical constructions, ed. Lourenço, P., Modena, C., Roca, P., pp. 63-73, Balkema, Amsterdam.

Coïsson, E., Ottoni, F., 2015. Structural Monitoring of Historical Constructions: Increasing Knowledge to Minimize Interventions, Built Heritage: Monitoring Conservation Management, Springer International Publishing, pp.83-92.

ICOMOS, Recommendations for the analysis, conservation and structural restoration of architectural heritage, Barcelona, 2005.
Coïsson, E., Ottoni, F., 2013. Il monitoraggio storico ovvero la lezione della storia agli strutturisti, Filosofia delle conservazione e prassi del restauro, Napoli, Arte Tipografica Editore.

Castellazzi, G., D’Altri, A.M., Bitelli, G., Selvaggi, I., Lambertini, A., 2015. From laser scanning to finite element analysis of complex buildings by using a semi-automatic procedure, Sensor, 15.

Shi G.H., Goodman, R.E., 1998. Generalization of twodimensional discontinuous deformation analysis for forward modeling, in Félix Darve, René de Borst, Andrew J. Whittle, Ronaldo I. Borja, Gilles Pijaudier-Cabot, Numerical and Analytical Methods in Geomechanics, 13(4).

Thavalingam, A., Bicanic, N., Robinson, J.I., Ponniah, D.A., 2001. Computational frame work for discontinuous modeling of masonry arch bridges, Computers \& Structures, 79(19).

Becci, A., Foce, F., 2002. Degli archi e delle volte. Arte del costruire tra meccanica e stereotomia, Venezia, Marsillo.

Giordano, A., Mele, E., De Luca, A., 2002. Modelling of historical masonry structures: comparison of different approaches through a case study, in Engineering Structures.

Lourenço, P.B., 2008. Structural masonry analysis: recent developments and prospects, University of Newcastle, Australia.

Casolo, S., 2009. Macroscale modeling of microstructure damage evolution by a rigid body and spring model, in Journal of Mechanics of Materials and Structures, 4(3).

van Noort, J.R., 2012. Computational modelling of masonry structures, Delft University of Technology, Faculty of Civil Engineering and Geosciences, Department of Design and Construction Section of Structural Mechanics.

Lourenço, P.B., Milani, G., Tralli, A., Zucchini, A., 2007. Analysis of masonry structures: review of and recent trends in homogenization techniques, Canadian Journal of Civil Engineering, 34.

Pelà, L., Bourgeois, J., Roca, J., Cervera, M., Chiumenti, M., 2006. Analysis of the Effect of Provisional Ties on the Construction and Current Deformation of Mallorca Cathedral, International Journal of Architectural Heritage.

Zerlenga, O., 2008. Rappresentazione geometrica e gestione informatica dei modelli, Napoli, La Scuola di Pitagora.

Caraccia, F., 2006. Metodi di modellazione NURBS con Rhinoceros, L'Aquila, Jonatek.

Coak, P., 2008. Rhinoceros NURBS modeling for Windows, Seattle, Robert McNeel \& Associates. 